Fecha de recepción: diciembre 2018 Fecha de aceptación: marzo 2019 Versión final: junio 2019

\section{Heroínas feministas en la historieta. Género, memoria y disidencia sexual en Dora de Minaverry}

Facundo Saxe*

Resumen: Este artículo aborda la emergencia de protagonistas / heroínas en la historieta argentina reciente, en particular el caso del cómic Dora de Ignacio Minaverry que cuenta hasta 2018 con tres tomos en circulación. Se analiza esta saga como parte de una constelación de apariciones de protagonistas mujeres sexo-disidentes en la historieta argentina reciente, diferente a la posición ocupada por personajes mujeres en épocas anteriores en la historieta. En ese sentido, el personaje de Dora podría apreciarse como parte de una producción de heroínas del siglo XXI en la historieta argentina. Éstas a diferencia de protagonistas femeninas de otros períodos son parte constitutiva de una modalidad cercana a una perspectiva de sexo-género feminista para el desarrollo de los relatos visuales propios del cómic. Dora es un personaje que construye un camino diferente y en algún sentido inusual para la historieta argentina tradicional y heteropatriarcal, se trata de una heroína de tiempos feministas, sexo-disidente y cuya historieta aborda temas de género. En ese marco, el cómic cruza la reflexión de una perspectiva de sexo-género con la memoria y temáticas icónicas de la historieta como el cómic de espías o el abordaje del pasado traumático. Dora es parte de una generación que muestra otras posibilidades para el cómic argentino, por lo que su aparición podría implicar un cambio en el horizonte de los relatos historietísticos argentinos. Temas como el afecto por fuera de la heteronorma, la disidencia sexual, el aborto, la identidad, la amistad, el lugar de la mujer en la historia, entre otros, forman parte de las aventuras de Dora hasta el momento.

Palabras clave: historieta - género - disidencia sexual - feminismos - Dora - Minaverry memoria - identidad - cómic reciente - Argentina

[Resúmenes en inglés y portugués en las páginas 107 - 108]

${ }^{(*)}$ Profesor y Doctor en Letras por las Universidad Nacional de La Plata, Investigador Asistente de CONICET y trabaja en el Centro Interdisciplinario de Investigaciones en Género (CInIG-IdIHCS). Profesor adjunto de Literatura alemana en la FaHCE-UNLP y docente del seminario de grado "Teorías queer". Ha dictado cursos vinculados a disidencias sexogenéricas, teorías queer y representaciones culturales (literatura-cine-historieta) de género y disidencias sexuales en distintas universidades del país. Temas de interés: estudios de género y sexualidades en la literatura, literatura comparada, historieta, textos culturales y disidencia de sexo-género, enfoques culturales transnacionales, memoria queer en representaciones culturales latinoamericanas y europeas. 


\section{Introducción}

Este artículo realiza una aproximación inicial al cómic Dora de Ignacio Minaverry, enmarcada en la idea de que este personaje es parte de una serie de emergencias de heroínas protagonistas en la historieta argentina reciente. Me interesa realizar un abordaje específico de diferentes rasgos del cómic desde una perspectiva feminista y sexo disidente, enmarcada en variantes teóricas como las teorías feministas y queer (Dorlin, 2009). Creo importante resaltar que el abordaje se centra en los tres primeros tomos aparecidos hasta el año 2018 de la saga de Dora, que actualmente se encuentra en proceso y contará con varios más. ${ }^{1}$ Considero que Dora forma parte de una constelación de apariciones de protagonistas mujeres en la historieta argentina reciente producidas desde derivas creativas vinculadas a perspectivas feministas y sexo-disidentes. Esta idea de mujeres protagonistas pensadas por fuera de una mirada heterosexista, masculina y patriarcal, aunque parezca obvia, en la historieta en general no ha sido tan habitual. Se puede ejemplificar fácilmente con el lugar que los personajes femeninos han ocupado en historietas de la tradición argentina o de otros espacios, donde hay una serie de estereotipos que construyen a la mujer en función de los personajes masculinos y de la mirada heterosexista y patriarcal. En función de estas cuestiones, creo que Dora como historieta y personaje puede ser parte de una producción de heroínas y protagonistas por fuera de esos mecanismos de la tradición heteropatriarcal en el cómic argentino, que se diferencian en varios casos en que son producidas a partir de un posicionamiento feminista vinculado con una perspectiva de sexo-género (Butler, 1990) en el desarrollo del relato textual y visual propio de la historieta. Me interesa hacer un análisis del caso Dora porque creo que funciona como punto paradigmático para pensar apariciones (que no serían del todo nuevas, pero sí durante mucho tiempo invisibilizadas, silenciadas o borradas) feministas y sexo-disidentes en un material tan complejo como el cómic.

\section{Cuestiones de género, heroínas y disidencias}

Pensar el lugar de las mujeres y las identidades feminizadas en la historieta argentina es adentrarnos en un campo donde los estereotipos sesgados y cargados de prejuicios han sido hegemónicos durante mucho tiempo. Por supuesto que ha habido resistencias a estas configuraciones de la mujer desde lugares estereotipados y sistematizados para una mirada masculina, heterosexual y patriarcal, pero históricamente la visión mayoritaria y dominante sobre las mujeres que aparecen en las historietas fue construida desde un sistema de estereotipos heteropatriarcales. Al respecto señala Mariela Acevedo:

Dice la leyenda que en el campo de las historietas las mujeres dibujadas siempre encarnan la fantasía más sensual o el miedo más pueril de los muchachos de carne y hueso: las hermosas suelen ser villanas hipersexualizadas más malas que las arañas, las heroínas son versiones devaluadas de un prototipo masculino y las compañeras -novias eternas- son pobres mujeres que caen en desgracia cada quince minutos para que ellos puedan lucir sus habilidades a la 
hora de resolver entuertos. Las que no se ajustan al canon de belleza son las matronas, gordas y ridiculizadas, siempre con un palo de amasar en la mano. Entre esos dos polos se han movido, con diferente suerte, las representaciones de lo femenino: Mujer fatal o la fatal mujer. La Pampita de Altuna o la Eulogia del Negro Fontanarrosa. (Acevedo, 2012: 10)

Siguiendo la línea trazada por Acevedo, Gabriela de Sousa Borges hace una sistematización de la representación de las mujeres en la tradición de la historieta y construye las siguientes categorías/estereotipos: las amas de casa, las sexualizadas, los personajes de reparto, las mujeres independientes, las mujeres típicas y libres (de Sousa Borges, 2014: 47 52). La última categoría va más de la mano de tiempos más recientes y de la construcción de auto-representaciones por parte de las mujeres historietistas que comienzan a disputar lugares en el campo del cómic masculino y patriarcal. Los tres primeros estereotipos, que configuran gran parte de la tradición de la historieta argentina, son una muestra de los lugares minoritarios, subalternos o prejuiciosos que ha ocupado la representación de las mujeres en la historieta argentina. Creo que también es importante resaltar las ausencias y dificultades que han existido para el desarrollo de creadoras mujeres en el campo de la historieta argentina, durante décadas considerado un espacio de varones heterosexuales en el que las mujeres (si los ocupaban) aparecían en lugares minoritarios o subalternos. Como señala de Sousa Borges tal vez la ausencia de creadoras tuvo un impacto directo en la construcción de estereotipos prejuiciosos y superficiales:

(...) es posible que la ausencia de mujeres autoras en la tradición de la historieta argentina, así como de las representaciones del universo femenino desde una mirada feminista, haya influido en la proliferación de personajes estereotipados. Sin embargo, esa tradición comienza a ser cuestionada con diferentes iniciativas a partir de los 80 , después con la aparición de trabajos independientes de autoras hasta la llegada de la revista Clítoris (...) (de Sousa Borges, 2014: 37)

De Sousa Borges también señala por un lado que las mujeres creadoras vienen a tensionar y disputar la hegemonía heteropatriarcal en la historieta desde los años ochenta, por otro que existe también un desarrollo paralelo en algunos creadores varones que van a posicionarse desde perspectivas que buscan ampliar la presencia de personajes femeninos desde perspectivas que confrontan directamente con el lugar que habitualmente tuvo la representación de las mujeres en la historieta argentina. Entre estos últimos de Sousa Borges destaca a Ignacio Minaverry:

Pero esa lucha de resistencia de las mujeres por más espacio en el universo de la historieta no es necesariamente paralela al trabajo de los hombres historietistas. Algunos de ellos también discuten esta problemática. En la actualidad Argentina, eso está claro como ejemplo en las historietas de Dora, de Ignacio Minaverry, una chica judía que trabaja como espía en Berlín post-guerra, pero que también vive aventuras sexuales. (de Sousa Borges, 2014: 44) 


\section{El caso Dora}

Dora se comienza a publicar en formato de tira seriada en la revista Fierro (segunda época) para luego ser editada en tomos que primero recopilan esos episodios y luego continúan con historias producidas específicamente para la circulación en esos volúmenes. Hasta el año 2018 se publicaron tres tomos de Dora: ${ }^{2}$ Dora * Número ${ }^{*}{ }^{\star} 20.874{ }^{*}$ Rat-Line (2009), Dora No 2 El año próximo en Bobigny 1962 (2012) y Dora malenki sukole 19631964 (2018). Según su creador, Ignacio Minaverry:

Dora es de los '60. Es una historia que empieza en el '59 y tiene fuertes rémoras de los '40, pero transcurre en los '60. La del '60 es la década que a mí más me gusta para dibujar, eso se ve también en Noelia, que está bastante inspirada en las historietas psicodélicas. En cuanto a Dora, la relación entre esas tres décadas es tensa, porque la gente de los '60 se está topando con algunos de los problemas que vienen de los '40 y que la gente de los '50 no se ocupó de solucionar. La idea básica de Dora es esa. (Minaverry en entrevista Schmirman, 2016: s/p)

Me interesa remarcar que Dora es un personaje que construye un camino que podríamos señalar como subversivo o contra-hegemónico para lo que fueron los relatos tradicionales de la historieta argentina en gran parte del siglo XX y parte del XXI. Pero creo que contextualizada podría ser un síntoma de un momento del cómic argentino que prefigura un horizonte feminista y sexo-disidente que podríamos estar atravesando. Con esto me refiero a que Dora es parte de una época en la que comienzan a aparecer creadoras, personajes y producciones feministas, sexo-disidentes y antipatriarcales en la historieta argentina, que disputan y tensionan con la tradición muchas veces heterosexista y patriarcal. Porque Dora es una historieta que aborda cuestiones de género cruzadas con temas como la memoria o el abordaje del pasado traumático así como temáticas tradicionales de algunos géneros de la historieta como puede ser la aventura de espías. En los tres tomos de Dora se pueden constatar una variedad de tópicos y temas que hablan del pasado pero también anclan el universo de la historieta en el contexto feminista reciente argentino: el afecto por fuera de la heteronorma, el aborto, la disidencia sexual, la identidad, el trauma colectivo, el lugar de las mujeres y colectivos subalternos en la historia, entre otros.

Dora no es casualidad, por un lado es parte de un momento feminista y sexo-disidente que vino a tensionar y disputar con la historieta heteropatriarcal tradicional, ${ }^{3}$ por otro, y teniendo en cuenta otras obras recientes, se podría aventurar que forma parte de una emergencia colectiva de subjetividades, posicionamientos e imágenes vinculadas al cruce entre temas de género, sexualidad y memoria. Se me ocurren dos ejemplos de esta cuestión: uno podría ser Notas al pie (2017) de Nacha Vollenweider, que desde la conformación de una subjetividad lesbiana configura un universo con una protagonista que cruza la historia personal con la colectiva, el pasado traumático de Alemania con la dictadura Argentina, sin dejar de visibilizar el protagonismo de una heroína lesbiana que hace dialogar el presente con el futuro y las imágenes del pasado alemán con el pasado argentino y el presente de ambos países; el segundo ejemplo es la historieta Camino a Auschwitz y otras historias de resistencia (2015) de Julián Gorodischer y Marcos Vergara, que a partir 
de posicionamientos autoficcionales sexo-disidentes construye una deriva personal que relaciona el pasado familiar con la Segunda Guerra Mundial y el pasado argentino, todo desde una subjetividad sexo-disidente que configura el universo del cómic. No creo que Dora sea una figura solitaria entre los personajes femeninos y sexo-disidentes protagonistas que aparecen en la historieta argentina de la última década, me parece que es parte de una avanzada que confronta el silenciamiento, disciplinamiento y estereotipación de la representación de las mujeres y las disidencias sexuales en la historieta desde posicionamientos feministas sexo-subversivos (Saxe, 2018: 4).

El trabajo que realiza Dora con el pasado no es algo nuevo en el mundo del cómic, que cuenta con uno de los antecedentes más importantes de tematización del pasado traumático vinculado al nazismo y el Holocausto, me refiero a Maus: A Survivor's Tale (1991) de Art Spiegelman. Dora, ambientada hasta el momento en los años sesenta, es una historieta vinculada al nazismo y el pasado pero desde un posicionamiento que podría indicar que hablar del pasado (nazismo, posguerra, años sesenta) es una forma de pensar el presente (en particular en el contexto argentino); ya que Dora visibilizando temas de la posguerra en varias de sus zonas temáticas parecería estar estableciendo un diálogo directo con el presente de la realidad argentina.

Por supuesto que Dora no es una historieta que reniegue del cómic, ya que desde cierta perspectiva es una obra de aventuras vinculada al subgénero de espías. Dora es una joven "caza-nazis" en la posguerra que recorre diferentes lugares del planeta. Formalmente el uso de los recursos narrativos visuales propios del cómic son parte de la riqueza creativa de Dora, ${ }^{4}$ como señala Acevedo:

Minaverry utiliza el espacio de la página de manera bastante libre. En la puesta en página podemos observar la disposición espacial de las viñetas y las diferencias de tamaño que ponen en tensión el hipercuadro -que conforma la página en su conjunto- con la unidad de la viñeta. Aunque las viñetas conforman una unidad están en relación de solidaridad no sólo con la secuencia lineal de lectura sino con el cuadro general de la página. (Acevedo, 2012: 19-20)

No se trata de una historieta que pretenda alejarse rotundamente de temas que aparecen en el mundo historietístico, la diferencia tal vez se encuentra en que lo hace desde una perspectiva feminista que pretende confrontar los lugares establecidos habitualmente para las mujeres en las historias "de espías". En Dora no hay una chica Bond que funcione como interés romántico del hombre de acción masculino o una mujer fatal que pretenda ser su perdición. Dora es la espía protagonista, la heroína que establece vínculos con otras mujeres y que a medida que avanza la acción del cómic presenta otros personajes femeninos con diferentes voces que son parte del colectivo de mujeres que protagoniza la saga de Dora. Tal vez toda esta cuestión de la perspectiva es parte de la conformación de Dora como historieta, quiero decir que puede que la aparición de este colectivo de voces de mujeres, así como una heroína protagonista como Dora se relacione directamente con que Dora es una historieta feminista, ya que su creador, Ignacio Minaverry, explícitamente se identifica como feminista, como señala en una entrevista realizada por Acevedo: 
- ¿Qué le dirías a alguien que leyera en tu obra cierta dimensión feminista en la forma de abordar temas y construir personajes?-

- Que yo soy feminista- (Minaverry en entrevista Acevedo, 2012: 9)

No es casualidad que la entrevista de la que proviene la cita sea Clítoris, una revista feminista de historietas cuyo tercer número (2012) contó con una tapa dibujada por Minaverry. En diferentes entrevistas Minaverry deja en claro su posicionamiento respecto a la presencia de personajes mujeres protagonistas que rompan con los estereotipos tradicionales de representación. Hay una visión por parte del autor de visibilización política de grupos subalternos o representados de formas sesgadas o patriarcales en la tradición normativa de la historieta:

Y la historia se fue convirtiendo en una historia de personajes que representan a alguna minoría, las protagonistas son dos chicas lesbianas: una judía y otra gitana que encima viven en monoblocs...bueno una no, una vive en una camioneta. Digamos que en la época de los nazis tenían todos los números de la rifa para irse a un campo de concentración, todos los triangulitos juntos. Y todos los personajes son de una ex colonia también. Y eso yo lo siento que es como hablar de la gente que vive en las villas o en los monoblocs, los últimos orejones del tarro. El sustento histórico que tiene es básico, es un escenario, Francia en esa época, más bien los suburbios de París en esa época, pero después muchas cosas que pasan... creo que son cosas que podrían llegar a pasar en un monobloc de acá. Y me parece que eso es también lo que pasa ahora, pensar en las necesidades de inclusión de quienes son los más postergados: los putos, transexuales, travestis. O lo que sucede con la Asignación Universal por Hijo. (Minaverry en entrevista Acevedo, 2012: 9)

En ese contexto, Dora se convierte en un vínculo por un lado con la representación de mujeres y disidencias sexuales, por otro en un texto que dialoga con el pasado muchas veces no representado por la historia o materiales culturales como la historieta, ¿cuántos relatos culturales de ficción existen sobre mujeres lesbianas en los años sesenta? A ese tipo de preguntas responde la presencia del trasfondo histórico de Dora, así como la enunciación en primera persona del personaje y otras mujeres. En ese sentido, como señala Latxague, "De testigo pasivo, Dora pasa a ser conservadora de la historia, registrar copias de lo que va descubriendo." (2018: s/d). O lo que podríamos pensar darle voz a colectivos que muchas veces no tuvieron voz ni fueron registrados por la historia como tales. Dora construye un pasado histórico vinculado a una historia que muchas veces no aparece en los relatos oficiales (y heteropatriarcales). Y se juega en el marco de una doble función, ver un pasado desde una perspectiva torcida (Llamas, 1998) que dialogue con nuestro presente (lo que muchas veces no se vio o no se pudo ver). Como señala Acevedo: "El autor considera que aunque sus historias remiten al pasado, de alguna manera siguen hablando de situaciones de desigualdades vigentes" (2012: 24). No es casualidad que toda la situación de la apro- 
piación de Lotte/Nina en el contexto de posguerra europeo nos remita a la apropiación de hijos en la dictadura argentina de los años setenta.

Volviendo a la cuestión de la perspectiva de sexo-género, Acevedo hace una lectura muy interesante sobre el lector de una obra como Dora, ya que analiza y propone que la historieta puede tener un destinatario sexuado mujer como posible lectora, principalmente porque en la historieta se ve una dislocación respecto a lo esperado por el lector típico tradicional (y muchas veces heteropatriarcal) de una revista como Fierro, de ahí que temas como el aborto aparezcan en Dora y sean tratados desde una posición de enunciación femenina: "La identificación que pretendería la tira es, con la posición de Odile, asumir el lugar de la mujer en el discurso, resulta por tanto lo más novedoso y arriesgado del relato." (Acevedo, 2012: 25). Dora construye representaciones de mujeres que ya no están pensadas desde los estereotipos de una cultura patriarcal y que no funcionan en torno a la mirada de un lector masculino heterosexista. En esta historieta, las políticas corporales de representación femenina se corren de los lugares de la tradición masculina patriarcal para pensar formas que buscan visibilizar otras formas de representación alejadas de estereotipos y miradas sesgadas o prejuiciosas:

La puesta en página de cuerpos que resultan disruptivos con el canon de belle$\mathrm{za}$ al que suelen adscribir las historietas en el momento de representar el cuerpo femenino se intuyen en elecciones estéticas como las pronunciadas caderas de Odile, la representación de chicas de estatura media, con kilitos o pelos en las piernas que contrastan con las representaciones más clásicas que se han hecho de las mujeres en las historietas. (Acevedo, 2012: 26)

\section{Derivas de una heroína feminista llamada Dora}

Como se viene señalando Dora es una obra multifacética, que tensiona con la tradición respecto a las normas heteropatriarcales de representación de personajes femeninos y sexodisidentes. El primer volumen ya sienta las bases de líneas que se siguen desarrollando en los dos tomos siguientes. Creo que es importante resaltar el posicionamiento de la producción de Minaverry respecto a voces y personajes que no han sido representados de forma masiva o central tanto en la historieta como en el canon histórico. Me refiero a que Dora sea una joven lesbiana, judía e hija de un personaje exterminado en el campo de concentración de Dora-Mittelbau. Nada es casual en el universo de Dora, como señala Latxague:

La novela gráfica empieza en Berlín, con el capítulo titulado “20874”, que corresponde al número de identificación de Iakó Bardavid en el campo de exterminio de Dora-Mittelbau. Entendemos por lo tanto que el nombre de Dora ha sido dado a la protagonista por su madre en memoria de esta funesta genealogía. (Latxague, 2018: s/p) 
Claramente, un rasgo de importancia de este primer volumen de Dora, que se relaciona con la construcción identitaria del personaje, es su nombre. Acevedo también señala el vínculo del nombre de Dora con el lugar de exterminio y el número de registro de su padre en el campo de concentración, así como la configuración de Dora como una protagonista femenina temáticamente vinculada con las historias de espías. Dora termina convirtiéndose en una especie de espía caza-nazis. Toda esta cuestión más cercana al subgénero de espías, se cruza con la temática histórica vinculada a los nazis y la situación de la posguerra en Europa. En la obra constantemente se remite a lo histórico, a veces por medio de materiales reales o que recrean episodios históricos y otras por medio de materiales ficcionalizados para parecer verosímiles en el marco histórico. Por ejemplo, aparece reproducido en una viñeta (con insignias, colores y datos de identificación) el cuadro "Insignias de los prisioneros de un campo de concentración" (estrella de David, triángulo rosa, triángulo rojo, triángulo negro, etc.).

En Dora 1 se presentan los rasgos generales de la heroína protagonista y algunos detalles que prefiguran el tipo de centralidad (y enunciación) que tiene Dora como personaje que rompe confronta con una forma de representación de las mujeres en la historieta. La presencia de una referencia a la película muda Die Büchse der Pandora (La caja de Pandora, 1929, dirigida por G. W. Pabst $)^{4}$ puede constituir un vector intertextual para reflexionar sobre la representación cultural de las mujeres. Latxague propone una relación entre esta imagen, Dora y el mito de Pandora para la configuración del personaje (Latxague, 2018: $\mathrm{s} / \mathrm{p}$ ). Creo además que se podría sumar una referencia a Lulu, la protagonista de la película representada (la "Pandora" del título): Lulu es una de las primeras mujeres fatales del cine, pero también es un personaje cuya sexualidad no responde a la norma y configura tanto en la obra teatral original como en la adaptación libre cinematográfica la representación de un personaje femenino que confronta contra los disciplinamientos del mundo heteropatriarcal y visibiliza derivas culturales lesbianas. No es casualidad que tal vez Dora en su primer volumen nos pueda recordar a esa Lulu que aparece en el afiche del filme en la historieta, Lulu es una mujer que rompe con la norma establecida y con la sexualidad, casi como vamos a ver ocurre con Dora en la historieta.

Acevedo marca algunas coordenadas específicas sobre la producción de Dora que arrojan más pistas sobre cómo se estaría produciendo en la obra de Minaverry un cruce entre el tema histórico, la memoria y la representación de un personaje femenino protagonista que no responde a la heteronorma o el lugar habitual de las mujeres en la historieta argentina "para varones":

Ignacio Minaverry había comenzado el relato de Dora por la historia de una espía que llegaba a la Argentina tras la pista de un filonazi, el antropólogo Otto Graff, que resultó ser la segunda historia que se publica en Fierro, "Rat-line". La historia del archivo de Berlín, "20874", fue escrita con posterioridad como comienzo del relato y coincide con la inquietud de Minaverry de situar las motivaciones personales de Dora en el período de desnazificación, para visibilizar las tareas de las nuevas generaciones frente al horror heredado. (Acevedo, 2012: 23) 
Resulta interesante que varias marcas temáticas y argumentales que aparecen en el primer tomo son retomadas en los siguientes. Por ejemplo, la relación con los padres de Lotte/ Nina, apenas subrayada en Dora 1 va a cobrar sentido cuando se descubre que son apropiadores en Dora 3: "Nuestros padres... ¿ iserán conscientes de las cosas que nos hacen?" (Minaverry, 2009: s/p) se pregunta en una viñeta Lotte en Dora 1, una frase que cobra otro sentido cuando nos enteramos en el tercer volumen de la apropiación de Lotte/Nina. Asimismo, el peso de las disputas generacionales y la relación con los padres es parte de la trama de los tres tomos publicados hasta el momento. No sólo por el vínculo de Dora con sus padres, su nombre y el vínculo con el Holocausto, sino también con datos como la relación de Lotte/Nina con sus padres y la tematización del choque generacional de los años sesenta (la generación del 68 alemán) con la generación de los padres que había apoyado al nazismo (situación ejemplificada con claridad en el caso del compañero de Lotte/Nina y sus padres). Dora es parte de la generación de los hijos, su padre fue asesinado en un campo de exterminio y ella trabaja en un archivo histórico donde comienza a construir su archivo de datos sobre nazis. Pero no se trata sólo de un archivo de datos, también es un archivo vital que tiene que ver con su propia historia: “¿Sabés por qué me llamo "Dora"? ¿Por qué?/Por el campo "Dora-Mittelbau", adonde llevaron a mi padre/Mamá me puso ese nombre para que nunca me olvide de dónde vengo. (Minaverry, 2009: s/p)

La perspectiva de sexo-género feminista de Minaverry aparece de forma constante en los tres tomos, la situación del aborto de Odile en el segundo tomo es un ejemplo claro y hay una preocupación que el autor hace explícita al respecto: "Quería saber si lo había tratado bien, porque además no es usual que ese tipo de temas salgan en una historieta, por lo menos en la Fierro o en las historietas argentinas en general." (Minaverry en entrevista Acevedo, 2012: 8). La perspectiva de sexo-género se configura con determinación desde Dora 1. La centralidad de la voz narrativa de Dora así como la preponderancia de los personajes femeninos es más que evidente. Las mujeres llevan la acción adelante y los personajes masculinos son secundarios, acompañan o funcionan como externos a la centralidad del relato. En Dora 2 se sigue desarrollando esta idea con la inclusión de nuevas voces narrativas, pero todas configuradas en mujeres que enuncian en primera persona pero no habitan lugares hegemónicos de la tradición masculina y patriarcal de representación de las mujeres en la historieta (Odile, Geneviève). Como señala al respecto Latxague:

A diferencia de la narración en primera persona del primer tomo de la novela gráfica, en el segundo se suman dos nuevas voces narrativas en Dora. Primero, la de Odile, quien tras la decepción sentimental con Didouche, amigo de infancia argelino militante del FLN, y un aborto clandestino, decide empezar estudios en la universidad. Ella es quien encarna más claramente el fenómeno transclase y la emancipación feminista. La segunda voz, es la de Geneviève, primer amor de Dora, cuya construcción identitaria sigue el movimiento contrario al de la heroína: huérfana de padres, se ha criado en un espíritu de libertad sin sentir el peso de la historia y cultivando, a su manera, la relación son sus orígenes. (Latxague, 2018: s/p) 
En Dora 2 aparecen estas otras voces narradoras femeninas, los personajes masculinos aparecen pero siguen ocupando lugares menores dentro del relato. La introducción de Geneviève permite continuar con el posicionamiento feminista sexo-disidente, es otra voz narrativa como Dora, mujer, lesbiana y gitana, como para seguir continuando con la representación de personajes muchas veces considerados subalternos dentro de la hegemonía de la historieta y la historia. En ese sentido, la presencia de disidencias sexuales, políticas y étnicas es parte de la configuración de Dora como una historieta feminista y sexo-disidente. Geneviève es gitana, lesbiana, precaria y su familia fue exterminada por los nazis, resulta evidente que la historieta se ocupa también de las invisibilizaciones históricas.

La representación visual propia de la historieta también construye momentos sexo-afectivos entre ambas desde una perspectiva propia de personajes femeninos construidos para una mirada que busca escapar a la heteronorma patriarcal. No se evita el abordaje de las situaciones sexuales (por ejemplo Dora se masturba en varias ocasiones) pero el relato visual escapa a cualquier tipo de construcción llevada adelante para un lector masculino, sexista y heteropatriarcal. También se puede pensar que hay una suerte de deconstrucción de la idea de amor romántico, así como una confrontación con la ficción de heterosexualidad compulsiva en tanto supuesta normalidad de los vínculos humanos; en el universo de Dora se podría pensar que los vínculos heterosexuales no funcionan demasiado bien. Asimismo el vínculo lesbiano entre Dora y Geneviève se aleja de cualquier idea de perfección idílica y se construye en términos de ruptura con las ficciones de heterosexualidad, hay ternura pero complejizada. Al mismo tiempo la relación entre dos mujeres no aparece construida ni como una imitación de la pareja heterosexual ni para una mirada heterosexista (algo habitual en algunas representaciones heteropatriarcales de la representación de las relaciones sexo-afectivas entre mujeres lesbianas). La representación de la relación sexual en Dora 2 entre Dora y Geneviève no escapa a la práctica sexual ni a la sensualidad, se visibiliza su deseo por otras mujeres: "Después de que terminamos de hacer el amor, el estremecimiento sigue en forma de palabras, de miradas y de caricias. (...) en $2^{\circ}$ año me enamoré de una profesora, la señorita Merle, y no entendí que era lo que me pasaba." (Minaverry, 2012: s/p). Y no sólo Dora o Geneviève son personajes "torcidos" respecto al universo habitual de representación de las mujeres, también personajes que pueden aparecer como anecdóticos o secundarios como Madame Junot, la mujer barbuda y madre adoptiva de Geneviève, son parte de este cosmos de personajes en el que las mujeres siempre aparecen empoderadas, con mayor relevancia y dimensión que los personajes varones. La construcción de una perspectiva feminista que está configurada desde el punto de vista de los personajes femeninos (sin ser representados para una mirada heterocentrada y patriarcal) es constante a lo largo de los tres tomos de Dora. Desde el ya mencionado aborto de Odile (que está narrado desde su punto de vista) o el momento en el que se mencionan los "piropos" o dichos sexistas de varones a mujeres en la vía pública. El punto de vista siempre es femenino, Dora explícitamente narra que los hombres la miran pero no se animan a decirle porquerías porque parece "una chica seria". La enunciación es construida desde la posición de Dora y desde una perspectiva feminista que repiensa el lugar de la mujer en la historieta (y en la sociedad). 
Como ya señalé Dora 3 mantiene el tono de los tomos anteriores pero le da mayor entidad y relevancia al personaje de Lotte/Nina, en una línea que retoma y desarrolla el vínculo de este personaje con sus padres. Estas cuestiones sirven al relato para abordar líneas temáticas vinculadas al pasado nazi, al trauma histórico y diferentes situaciones de la posguerra europea, que además sirven como reflejo para pensar la historia argentina. Me refiero a que en Dora 3 se descubre que la amiga de Dora, Lotte, en realidad se llama Nina y fue apropiada en el contexto de la Segunda Guerra Mundial. La línea de acción que se desarrolla tiene que ver con las llamadas Lebensborn, un tema histórico vinculado al nazismo que tiene que ver con la apropiación de niños por parte de nazis o colaboradores del nazismo. En el caso de Lotte/Nina el relato ficcionaliza la situación histórica de niños polacos apropiados por los nazis. La situación en el relato aparece constantemente producida para visibilizar temas históricos con escasa o nula representación en la historia o en materiales culturales de ficción. Y también se evidencia cómo funciona toda esta situación como reflejo de la apropiación de niños en la dictadura argentina de los setenta: "No sabía que los nazis también hacían eso..." (Minaverry, 2018: 15). Hay un trabajo de investigación por parte del autor en torno al tema de la identidad y cómo emerge el recuerdo-identidad de la persona apropiada. “¿Soy un sueño o un recuerdo?” (Minaverry, 2018: 51) se pregunta Lotte/Nina mientras emerge en su mente la frase "malénki sukole" (que da título a Dora 3): el recuerdo de una canción que funciona como disparador para que Lotte/Nina comience a recordar y entienda de dónde proviene. El relato habla de la apropiación de las lebensborn pero constantemente parece que estuviera refiriendo a situaciones del pasado traumático argentino, se habla de cómo los apropiadores niegan o justifican, cómo obligan a Lotte/Nina a ocultar quién es (la hacen ocultar su marca de nacimiento), etc. El punto culminante sigue formando parte de estos paralelismos, porque cuando Lotte/Nina se reencuentra con su madre polaca que la buscó durante toda su vida parece que estamos ante los reencuentros con niños apropiados durante la dictadura argentina. ${ }^{7}$ Y así como Dora construye un archivo material pero también personal y afectivo para reconfigurar su historia y su pasado como hija de un padre exterminado en el Holocausto, Lotte no recuerda su identidad como Nina pero en el reencuentro aparece algo en el archivo psíquico (Derrida, 1995) que se dispara a partir de la frase de la canción infantil: “¿Quién sos vos?!/¿NO TE ACORDÁS DE MÍ?/¡No me acuerdo de nada!” (Minaverry, 2018: 83). El pasado aparece en la vida de las heroínas protagonistas como parte de una reconfiguración del universo y una forma de visibilizar temas muchas veces subrepresentados que dialogan con nuestro presente.

Dora es una obra de una riqueza y una complejidad considerables que configuran representaciones feministas de todo un colectivo de mujeres protagonistas al mismo tiempo que retoma temas históricos muchas veces poco explorados por la historieta o por disciplinas como la historia o la literatura canónicas y tradicionales. En ese sentido es que Dora se construye como una obra con un posicionamiento político feminista y sexo-disidente que tensiona y confronta con los disciplinamientos, omisiones y represiones de una sociedad heteropatriarcal. No es casualidad que en Dora 3 haya referencias a artistas y dibujantes mujeres polacas, ${ }^{8}$ Dora es un proyecto creativo que hasta en sus más mínimos detalles está pensando cómo funciona la representación de las mujeres en la tradición de la historieta y pretende formar parte de un cambio de época para esa representación. 


\section{Una historieta feminista-disidente}

Dora es una obra integral, feminista y con posicionamientos críticos del canon histórico y cultural, con una representación configurada desde esas perspectivas que busca confrontar con los mecanismos de normalización y exclusión de la cultura heteropatriarcal. Me interesa señalar al respecto las conclusiones de Latxague sobre Dora:

A través de personajes femeninos marginados, propone una lectura transhistórica de los inicios de la década del sesenta en Alemania, Argentina y Francia, estableciendo paralelismos a partir del ocultamiento y la clandestinidad como motores de la historia no oficial. El personaje de Dora, gracias a su plasticidad y capacidad de adaptación, se mantiene en equilibrio entre la observación y acción, entre la búsqueda de su propia identidad y la construcción de una sororidad, entre la conservación de la historia pasada y el testimonio más reciente. (Latxague, 2018: s/p)

La representación de personajes subalternos o minoritarios para la tradición de representación de la historieta y las "historias oficiales" no es casualidad, por un lado estamos ante un creador que se posiciona como feminista y que está articulando la construcción de una voz enunciadora que muchas veces no fue representada en la historieta argentina. Este artículo no pretende agotar las posibilidades en torno a Dora, sino simplemente pensar una primera aproximación a los cruces entre la representación de los personajes femeninos, la memoria y la perspectiva feminista. Acevedo (2012: 27) señala cómo en Dora hay una suerte de trastocamiento, el cuerpo y la sexualidad de "mujeres dibujadas" cambia, ya no estamos ante los estereotipos pensados para una mirada masculina, hay un cambio, una alteración del orden heteropatriarcal de representación del cuerpo y la sexualidad de las mujeres:

Finalmente, el cuerpo y la sexualidad de mujeres dibujadas se ve trastocado. Ellas han solido ser las encargadas de encarnar diversas fantasías o miedos masculinos (...) Pero el esquematismo entre la mujer fatal o la fatal mujer se ve conmovido con la historia de Dora. Las chicas Minaverry comenzaron por hablar de "cosas de mujeres": política, cambio social, pasado reciente, y por supuesto, sexualidad, amor, deseo. (Acevedo, 2012: 27) ${ }^{9}$

Dora es una obra escrita por un creador que asume una posición feminista que piensa tanto la representación de las mujeres como los temas que muchas veces no han aparecido en la hegemonía tradicional de una historieta a menudo patriarcal y heterosexista. Y coincido con Acevedo cuando señala que este pasado ficcionalizado en Dora tiene un reflejo directo en nuestro presente: temáticas ausentes en las historietas de espías clásicas como aborto, sexualidad disidente, heteronorma y luchas que producen ecos en la memoria y dialogan con nuestro presente (Acevedo, 2012: 27). Por eso mismo no es casualidad que Minaverry realice la tapa del número 3 de la revista Clítoris. Se trata de un compromiso político con la representación sexo-política de mujeres desde perspectivas 
feministas en la historieta. La tapa de Minaverry en una revista de historietas con una perspectiva feminista que piensa el lugar de las mujeres creadoras en la historieta y la representación así como la tradición (y la disputa) no es casualidad. No se trata de una tapa habitual realizada para una mirada masculina heterosexista (como pueden haber sido mucha de las tapas realizadas en revistas como Fierro), como señala de Sousa Borges: "Como los senos en la tapa del número 3, dibujada por Ignacio Minaverry, que expone el cuerpo de la mujer, sin mostrar ella como un objeto de deseo masculino. Al contrario, ella se presenta en una actitud combativa, mirando al público de frente." (2014: 77).

Dora es una historieta feminista. Es una historieta que trabaja desde la investigación histórica del pasado temas poco abordados así como perspectivas que en la historieta tradicional muchas veces han sido subalternas. A partir de esos rasgos se podría señalar que hay algo de valor histórico/testimonial, no porque Dora sea una historieta histórica, es una ficción pero su recreación de temas históricos puede convertirse en una forma de representar lo que muchas veces no aparece en la historia o los relatos oficiales. ${ }^{10}$

Y Dora se trata, como ya señalé, de una obra en proceso, actualmente en producción. Minaverry ha explicitado que Dora es una obra con varios volúmenes más por venir. En febrero de 2019 en su blog (minaverry.wordpress.com) dio a conocer que está listo el cuarto tomo de Dora, titulado Amsel, Vogel, Hahn.

Para concluir esta aproximación inicial a los tres primeros tomos de Dora, me interesa resaltar que Dora construye un archivo propio, como ya vimos un archivo de datos para "cazar nazis" y encontrar relatos vinculados a la verdad de diferentes sujetos, ella misma incluida. Pero también creo posible señalar que existe otro archivo, me gustaría pensar que la trayectoria de Dora se vuelve una forma de archivo, ya no un archivo material si no una suerte de archivo psíquico (Derrida, 1995); o en términos de la teórica y activista lesbiana val flores un "archivo del mal": aquello que se guarda, que resiste el flujo de la desaparición, que por alguna razón permanece, se atesora, se cultiva, se preserva” (flores, 2013: 187), una modalidad de archivo de libertad y subversión que contiene la trayectoria emancipadora y sexo-disidente de Dora y su universo de representaciones, que transcurre en los años sesenta pero es un reflejo de la Argentina del siglo XXI. Porque ese archivo que se vuelve Dora-personaje con su vida es una constelación de temas y apariciones que construyen a Dora-historieta, un material cultural que puede ser una forma de archivo multidireccional y contra-hegemónico, feminista y antipatriarcal de los tiempos que estamos viviendo y los horizontes por venir. Porque Dora, con su modalidad afectiva de representación de las mujeres y la disidencia sexual, construye un tipo de heroína feminista y lesbiana que desestabiliza, disputa y tensiona la tradición de representación heteropatriarcal de las mujeres en la historieta argentina.

\section{Notas}

1. En la presentación del tercer tomo de Dora realizada en Fábrica de Historietas (Ciudad de Buenos Aires) el viernes 18 de mayo de 2018 Minaverry comentó que hay material pensado para varios tomos más de la saga de Dora. Fui invitado por Hotel de las Ideas como entrevistador de Minaverry como parte de la presentación. 
2. Las llamaré respectivamente Dora 1, Dora 2 y Dora 3 para simplificar las menciones en este artículo.

3. La revista de historieta feminista Clítoris (dirigida por Mariela Acevedo) es uno de los ejemplos más importantes al respecto.

4. Claire Latxague vincula la construcción de los espacios con el trabajo sobre la memoria que realiza la obra: "Los espacios urbanos en los que se desarrolla la acción son todos espacios en mutación, que conservan los restos de un pasado a medio ocultar. Minaverry reproduce su arquitectura de manera hiperrealista, a partir de fotografías, poniendo de realce su propio trabajo de documentación en paralelo al que realiza su personaje de ficción." (Latxague, 2018: s/p).

5. La película de Pabst es la adaptación libre de dos obras de teatro del dramaturgo Frank Wedekind, que justamente tematiza tensiones vinculadas a la representación de las mujeres y el avance del movimiento feminista a fines del siglo XIX en Europa.

6. En la presentación mencionada en la nota 1 así como en diferentes entrevistas Minaverry ha manifestado que hay un trabajo de investigación histórica detrás de cada capítulo de Dora. Algo que también queda en evidencia en los agradecimientos de cada volumen.

7. Para el trabajo de descubrimiento de su identidad en Lotte/Nina Minaverry investigó en los procesos personales y colectivos alrededor de la recuperación de la identidad por parte de nietos apropiados en la dictadura argentina de los años setenta. Uno de los casos que aparece en los agradecimientos de Dora 3 es el de Ángela Urondo Raboy, la hija del escritor Francisco "Paco" Urondo, desaparecido por los militares en la dictadura.

8. En las páginas 94 y 95 aparecen reproducidos en la viñeta dibujos de las artistas polacas Irena Janczewska y Zofia Fijalkowska.

9. Acevedo desarrolla la idea de "Las chicas Minaverry" como forma de presentar esta representación feminista de las mujeres en la historieta: "Las chicas Minaverry" habían llegado para hablar de cosas de mujeres: política, cambio social, pasado reciente -y por supuesto- sexualidad, amor, deseo; para enfrentar algunas situaciones que no suelen entrar en las historietas de espías "para chicos": aborto, sexualidad disidente, heteronorma y para llevarnos de viaje por la Europa de fines de los 50 y a la Buenos Aires de la resistencia peronista." (Acevedo, 2012: 10).

10. Se advierte por ejemplo en la mención de Minaverry (en la entrevista mencionada en la nota 1) vinculada a que en futuros capítulos de Dora se va a abordar el tema de los testimonios de los triángulos rosa sobrevivientes a los campos de concentración nazis. Recordemos que con esa etiqueta (que aparece en el cuadro de símbolos de los campos reproducido en Dora 1) se marcaba a los prisioneros homosexuales.

\section{Lista de Referncias Bibliográficas}

Acevedo, M. (2012). “iQueremos tanto a Dora!” en Revista Clítoris, No 3, Buenos Aires, pág. 11.

Acevedo, M. (2012). "Entrevista a Ignacio Minaverry: 'me planteé dibujar mujeres, no muñequitas" en Revista Clítoris, No 3, Buenos Aires, pp. 8-10. 
Acevedo, M. (2012). “Una aproximación a las geografías imaginarias en la obra de Ignacio Minaverry" en Cultura, Lenguaje y Representación / Culture, Language and Representation, vol. X, Revista de Estudios Culturales de la Universitat Jaume I, pp. 15-34.

Butler, J. (1990), Gender Trouble. Feminism and the Subversion of Identity. New York: Routledge.

de Sousa Borges, G. (2014). "Encuentre su Clítoris" Observaciones sobre una revista de historieta de género en Argentina. Tesis de Maestría. Buenos Aires: FLACSO. Disponible en: https://repositorio.flacsoandes.edu.ec/handle/10469/8588 [15 de marzo de 2019].

Derrida, J. (1997 [1995]). Mal de archivo. Una impresión freudiana. Madrid: Trotta.

Dorlin, E. (2009). Sexo, género y sexualidades. Buenos Aires: Nueva visión.

Flores, V. (2013). "Masculinidades de niñas: entre "mal de archivo" y "archivo del mal"” en flores, valeria/tron, fabi (comp.) Chonguitas: masculinidades de niñas. Neuquén: La Mondonga dark, pp. 181-195.

Latxague, C. (2018) “Dora de Minaverry. Itinerarios de una heroína trans" en Babel. Littératures Plurielles [En línea], № 37. Disponible en: http://journals.openedition.org/ babel/5305 [15 de marzo de 2019].

Llamas, R. (1998). Teoría torcida. Prejuicios y discursos en torno a "la homosexualidad". Madrid: Siglo Veintiuno de España Editores.

Minaverry, I. (2009). Dora ${ }^{\star}$ Número $1{ }^{\star} 20.874{ }^{\star}$ Rat-Line. Buenos Aires: La Editorial Común. Minaverry, I. (2012). Dora No 2 El año próximo en Bobigny 1962. Buenos Aires: La Editorial Común.

Minaverry, I. (2018). Dora malenki sukole 1963-1964. Buenos Aires: Hotel de las Ideas/La Maroma Editora.

Saxe, F. (2018). "La trampa mortal: derivas maricas de la disidencia sexual en la producción de conocimiento científico al recuerdo infantil de un beso" en Etcétera. Revista Del Área De Ciencias Sociales Del CIFFyH, No 3, Córdoba: UNC. Disponible en https://revistas. unc.edu.ar/index.php/etcetera/article/view/22591 [15 de marzo de 2019].

Schmirman, C. (2016). "Entrevista a Ignacio Minaverry. El amo de Los Cosos" en Revista Arte Críticas, octubre, Buenos Aires: Universidad Nacional de las Artes. Disponible en: http://repositorio.una.edu.ar/handle/56777/993 [15 de marzo de 2019].

\begin{abstract}
This paper deals with the emergence of protagonists / heroines in the recent argentin comic, in particular the case of Dora, create by Ignacio Minaverry and that counts until 2018 with three volumes in circulation. In this paper, this saga will be analyzed as part of a constellation of protagonic appearances by sex-dissident women in the recent argentin comic, wich is different from the position occupied by female characters in other times in the comic. In that sense, the character of Dora could be seen as part of a production of heroines of the 21st century in the argentine comic industrie. Unlike female protagonists of the heterosexist male tradition, the Dora's comic is produced from a feminist sex-gender perspective. Dora is a character who constructs a different way for the traditional and heteropatriarchal argentin comic, she is a heroine of feminist times and whose adventures deals with gender issues. In this context, the comic crosses the reflection of a sex-gender
\end{abstract}


perspective with the memory and iconic themes of the comic strip, such as the spy comic or the approach to the traumatic past. Dora is part of a generation that shows other possibilities for the argentine comic, so the appearance of characters like Dora could imply a change in the horizon of Argentine historical stories. Topics such as affection outside the heteronorm, sexual dissidence, abortion, identity, friendship, the place of women in history, among others, are part of the adventures of Dora in these three volumes.

Keywords: comic - gender - sexual dissidence - feminisms - Dora - Minaverry - memory identity - recent comic - Argentina.

Resumo: Este artigo trata do surgimento de protagonistas / heroínas no recente comic argentino, em particular o caso da história em quadrinhos Dora, feita por Ignacio Minaverry e que conta até 2018 com três volumes em circulação. Neste artigo, essa saga será analisada como parte de uma constelação de aparições de mulheres protagonistas sexo-dissidentes no recente comic argentino, diferente da posição ocupada por personagens femininas em épocas anteriores nos quadrinhos. Nesse sentido, o caráter de Dora poderia ser visto como parte de uma produção de heroínas do século XXI no comic argentino. Estes, ao contrário de protagonistas femininos de outros períodos, são parte constitutiva de uma modalidade próxima a uma perspectiva feminista de sexo-gênero para o desenvolvimento das próprias histórias visuais da história em quadrinhos. Dora é uma personagem que constrói um desenho diferente e incomum para o comic tradicional e heteropatriarcal argentino, ela é uma heroína de tempos feministas, sexo-dissidente e cuja história em quadrinhos lida com questões de gênero. Nesse contexto, a obra cruza a reflexão de uma perspectiva de sexo-gênero com a memória e os temas icônicos da história em quadrinhos, como o comic dos espiões ou a abordagem do passado traumático. Dora faz parte de uma geração que mostra outras possibilidades para o comic argentino, então a aparição de personagens como Dora poderia implicar uma mudança no horizonte das histórias em quadrinhos argentinas. Temas como afeto fora do heteronorma, dissidência sexual, aborto, identidade, amizade, o lugar da mulher na história, entre outros, fazem parte das aventuras de Dora nesses três volumes.

Palavras chave: história em quadrinhos - gênero - dissidência sexual - feminismos - Dora - Minaverry - memória - identidade - quadrinhos recentes - Argentina

[Las traducciones de los abstracts fueron supervisadas por el autor de cada artículo] 